\title{
A FOUR-CHANNEL BIPOLAR MONOLITHIC PREAMPLIFIER FOR RHIC DIMUON PAD READOUT*
}

\author{
C. L. Britton, Jr., E. J. Kennedy $†$, R. A. Todd, A. L. Wintenberg, G. R. Young
}

Oak Ridge National Laboratory

Instrumentation and Controls Division

P. O. Box 2008, Oak Ridge, TN 37831-6006

\author{
†Electrical and Computer Engineering \\ The University of Tennessee \\ Knoxville, TN 37996-2100
}

\section{Abstract}

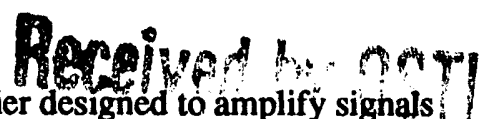

This paper presents a four-channel, low power-consumption bipolar monolithic preamplifier designed to amplify sighals
m pads with detector capacitance values from $10 \mathrm{pF}$ to $50 \mathrm{pF}$ used in a RHIC (Relativistic Heavy Ion Collider) dimuon experiment. The circuit utilizes a folded-cascode topology with a novel feediorward compensation \&! @improves the lowcapacitance transient response and provides self-biasing without resorting to bandgap or current references. The circuit was fabricated by Harris Semiconductor in the VHF dielectrically isolated complementary bipolar process. Measured data for gamma irradiation to $1.25 \mathrm{MRad}$ are presented.

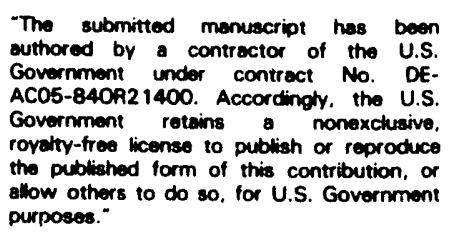

DISCLAIMER

\begin{abstract}
This report was prepared as an account of work sponsored by an agency of the United States Government. Neither the United States Government nor any agency thereof, ior any of their employees, makes any warranty, express or implied, or assumes any legal liability or responsibility for the accuracy, completeness, or usefulness of any information, apparatus, product, or process disclosed, or represents that its use would not infringe privately owned rights. Reference herein to any specific commercial product, process, or service by trade name, tra temark, manufacturer, or otherwise does not necessarily constitute or imply its endorsement, recommendation, or favoring by the United States Government or any agency thereof. The views
and opinions of authors expressed herein do not necessarily state or reflect those of the mendation, or favoring by the United States Government or any agency thereof. The. views
and opinions of authors expressed herein do not necessarily state or reflect those of the United States Government or any agency thereof.
\end{abstract}

*Research sponsored by the U. S. Department of Energy. The Oak Ridge National Laboratory is operated by Martin Marietta Energy Systems, Inc. for the U. S. Department of Energy under Contract No. DE-ÁC05-840R21400

-imarager (C. Fintion wiel cartict) 


\title{
A FOUR-CHANNEL BIPOLAR MONOLITHIC PREAMPLIFIER FOR RHIC DIMUON PAD READOUT*
}

\author{
C. L. Britton, Jr., E. J. Kennedy $\dagger$, R. A. Todd, A. L. Wintenberg, G. R. Young
}

Oak Ridge, National Laboratory

Instrumentation and Controls Division

P. O. Box 2008, Oak Ridge, TN 37831-6006
†Electrical and Computer Engineering
The University of Tennessee
Knoxville, TN 37996-2100

\section{Abstract}

This paper presents a four-channel, low power-consumption bipolar monolithic preamplifier designed to amplify signals from pads with detector capacitance values from $10 \mathrm{pF}$ to $50 \mathrm{pF}$ used in a RHIC (Relativistic Heavy Ion Collider) dimuon experiment. The circuit utilizes a folded-cascode topology with a novel feedforward compensation that improves the low-capacitance transient response and provides self-biasing without resorting to bandgap or current referenc $: s$. The circuit was fabricated by Harris Semiconductor in the VHF dielectrically isolated complementary bipolar process. Measured data for gamma irradiation to $1.25 \mathrm{MRad}$ are presented.

\section{INTRODUCTION}

The proposed pad readout chip architecture for RHIC experiments shown in Fig. 1 includes preamplifiers, analog memory, A/D converter circuitry, and appropriate tagging and crossing-select circuitry. Two approaches were considered for implementation: a consolidated readout with the preamp through the $A D C$ on one chip, and a distributed readout where memory through the ADC was separate from the preamp chip.

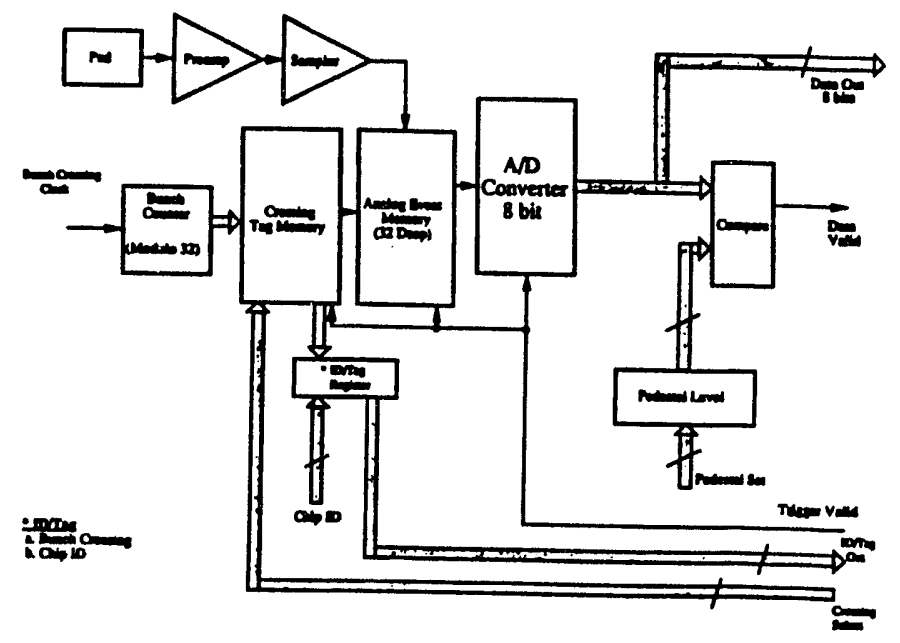

Fig. 1 Proposed Pad Readout Chip Architecture

*Research sponsored by the U. S. Department of Energy. The Oak Ridge National Laboratory is operated by Martin Marietta Energy Systems, Inc. for the U. S. Department of Energy under Contract No. DE-AC05-84OR21400
A consolidated solution was considered advantageous because there were few off-chip analog signals and the system cost might be reduced, but possibly it was not the best partitioning of technologies with respect to speed and noise, because the preamplifier could be implemented in bipolar with lower noise and higher speed. The distributed readout approach would likely optimize each portion of the system at the cost of a larger wiring plant and higher expense.

To implement the preamplifier for the distributed readout, a design was submitted as part of the Oak Ridge National Laboratory (ORNL) beta site test of the Harris FASTRACK software. This test resulted in a multiproject 10-wafer run with Harris as well as review of the software operation. The Harris system process was considered to be a candidate for the high-energy and heavy-ion physics environment because of its high bandwidth, low noise, and radiation tolerance characteristics ${ }^{1}$, which are required of preamplifiers in highradiation environments such as electromagnetic or hadron calorimeters. Besides the pad readout preamplifier for RHIC, eight other circuits were implemented. Seven of these were preamplifiers for SSC-related work ${ }^{2}$, and one was for a nonDOE project.

\section{HARRIS FASTRACK SOFTWARE AND VHF PROCESS}

FASTRACK, a complete ASIC development system on a single industry-standard workstation, is configured around the Cadence Analog Artist tools and includes schematic capture, Harris' SLICE circuit simulator, Cadence waveform display, and layout tools with design rule checker as well as Cadence PD compare, which checks layout vs. schematic, and Cadence PD extract, which performs a layout component extraction. Extraction is helpful when simulating behavior of the layout with the parasitic wire capacitances included. Because of some problems with the $\mathrm{AC}$ analysis of an early Beta version of the SLICE circuit simulator, the simulated noise numbers quoted in this paper were obtained by using HSPICE. The statistical performance analysis capability available with FASTRACK allowed the designer to predict the performance spectrum and to estimate yield to any given specification such as noise, bandwidth, or power dissipation. The analysis uses correlated random number techniques in setting device parameter variations based on the manufacturing process statistics. 
The Harris. VHF process is a dielectrically isolated $20-\mathrm{V}$ bipolar process with transition frequency $\left(f_{T}\right)$ values of 1.2 $\mathrm{GHz}$ (npn) and $1.0 \mathrm{GHz}$ (pnp). Early voltages $\left(V_{A}\right)$ were nominally $90 \mathrm{~V}$ (npn) and $18 \mathrm{~V}$ (pnp), with nominal current gains of 150 (npn) and 125 (pnp). A p-channel JFET device, diffused and thin-film resistors, MOS capacitors, a zener diode, and manufacturing structures were also provided.

\section{PREAMPLIFIER CIRCUIT TOPOLOGY}

The circuit, shown in Fig. 2 , is essentially a folded-cascode amplifier with a diamond driver output stage. The primary amplification path is the cascode QIN1-Q1 and the output driver stage comprised of Q3, Q4, Q7, and Q8. DC Bias is provided by $\mathrm{Q} 2, \mathrm{Q}$, and $\mathrm{Q6}$, which are current sources, and $\mathrm{Q} 9-\mathrm{Q} 10$, which, in addition to their associated resistor and capacitor strings, provide both DC voltage bias and feedforward compensation. The gain of the $\mathrm{Q} 9-\mathrm{Q} 10$ paths at frequencies below $10 \mathrm{KHz}$ is approximately $5 \%$ of the main cascode path. The chip layout for a quad configuration (i.e., 4 preamps) is shown in Fig. 3. The feedback resistor and feedback capacitor are externally connected between the INPUT and OUTPUT terminals.

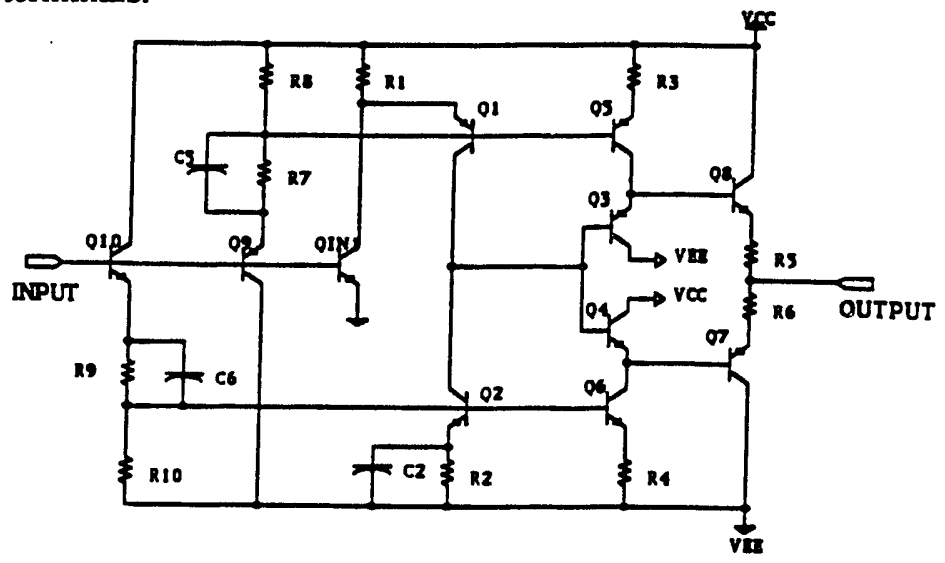

Fig. 2 Circuit schematic

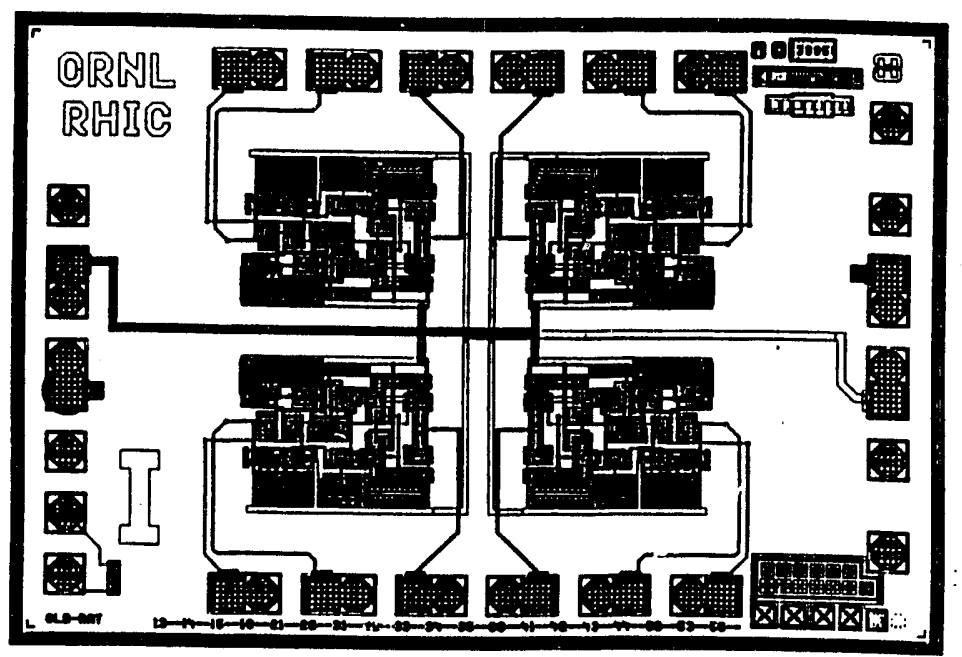

Fig. 3 Circuit layout
The large output charge of the pad system ( $-5 \mathrm{M}$ electrons/minimum innizing particle) required a preamplifier conversion gain of approximately $0.5-1 \mathrm{~V} / \mathrm{pC}$. This corresponded to a feedback capacitor of 1-2 pF. The input signal was to be similar to one already reported ${ }^{3}$ with a peaking time of $20 \mathrm{~ns}$ or less resulting in a slew-rate requirement, for $2 \mathrm{~V}$ output, of $\sim 100 \mathrm{~V} / \mathrm{hs}$. It should be noted that, for comparative purposes, the noise and risetime data reported in this paper are for input pulses of $\sim 1 \mathrm{~ns}$ risetime. Because of the large feedback capacitor (when compared to 0.1$0.3 \mathrm{pF}$ used in silicon strip and straw-tube front-ends), the resultant loop transmission can become high for small detector capacitances. The high loop transmission results in a fast rise time (assuming an appropriately fast transistor process has been employed) and a small phase margin. One constraint for this preamplifier was the required stability over a range of 10 to $50 \mathrm{pF}$ detector capacitance (CD). When designing with processes whose $f T$ is on the order of $1.4 \mathrm{GHz}$, the designer must keep in mind that these high transition frequencies occur not at 50-100 $\mu \mathrm{A}$, but closer to 0.5-1 mA. If any need for low power consumption exists, transistors will probably be operating with $f T$ closer to $300-500 \mathrm{MHz}$. In the case of this preamplifier, poles due to the transistor $f T$ began to be important at 300-500 MHz. Phase effects become apparent at frequencies lower than amplitude effects for most systems, so that even at $50 \mathrm{MHz}$ the $f T$ affects the overall phase margin. Typically, the overshoot of preamplifiers causes little problem with the resultant pulse response of the time-invariant, semigaussian filters that were planned for this system because the filter peaking time was 50 ns. The concern is therefore one of yield; with process variations that are inherent in any semiconductor process, how many preamplifiers will be made that are of adequate stability for all detector capacitances? We found that the resultant topology of Fig. 2 with feedforward via Q9 and Q10 increased the phase margin by $\sim 10^{\circ}$ with respect to a simple bias string for Q1. Simulations, shown in Fig. 4, reveal that this compensation has little effect below 10 $\mathrm{MHz}$ and begins to improve open-loop phase shift at around $50 \mathrm{MHz}$.

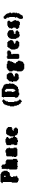

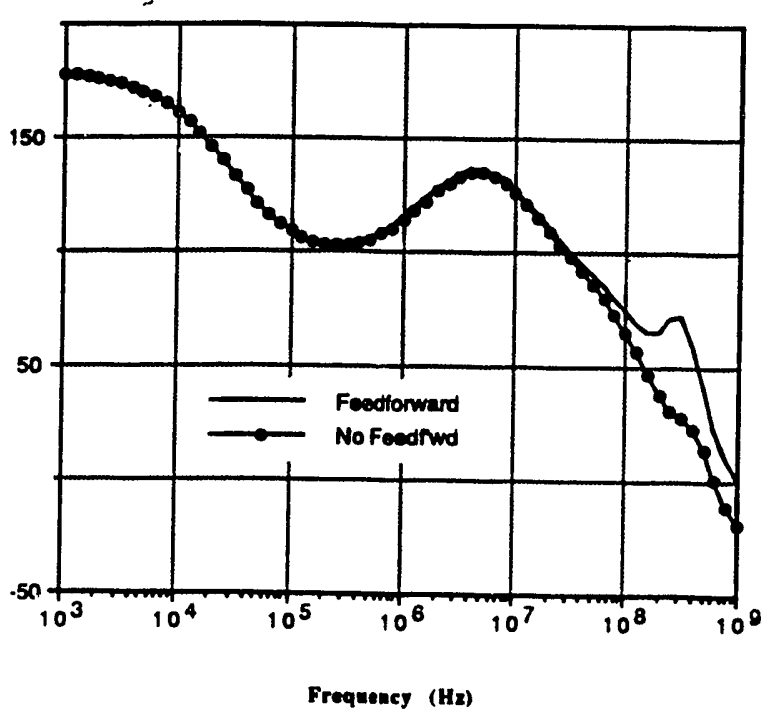

Fig. 4 Phase response simulations 
The midband phase response is dominated by an effect seen when using transistors having a low Early voltage in a cascode arrangement $t^{4}$. The input impedance at the emitter of $\mathrm{Q} 1$ is larger than simply $1 / \mathrm{gm}$ because of the collector-emitter resistance of $\mathrm{Q} 1\left(\mathrm{r}_{0}\right)$. This impedance is further increased by the fact that the resistance in the base of Q1 is unbypassed at midband frequencies. The "phase dip" apparent at $\sim 200 \mathrm{KHz}$ in Fig. 4 is due to the interaction of the changing impedance at the collector of Q1 above the dominant pole and its effect, due to feedback of $r_{01}$, on the impedance at the emitter of Q1. The pole-zero pair due to $c_{o 1}-r_{b 1}{ }^{5}$ of Q1 are almost coincident and thus have little effect on the overall phase. The experimentally observed transient response for the preamp is shown in Fig. 5.

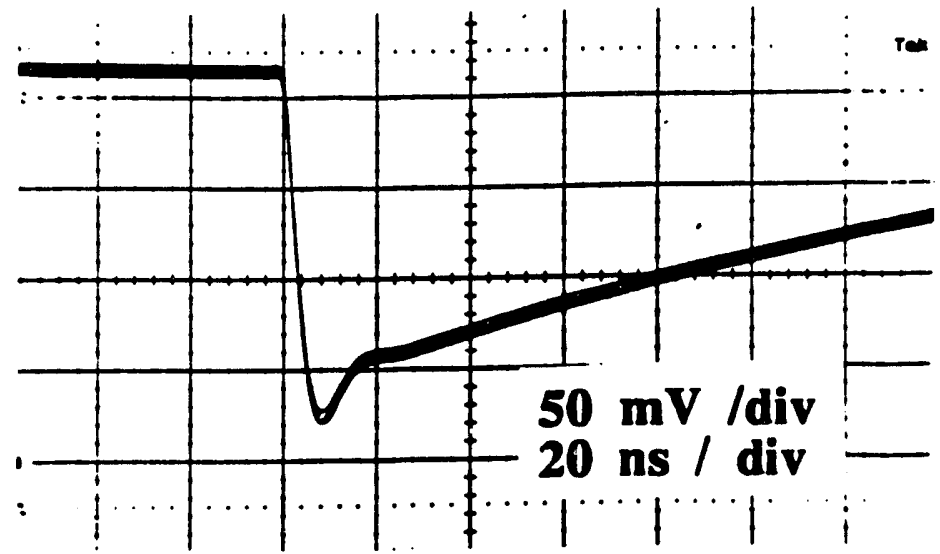

Fig. 5 Output for $\mathrm{CD}=10 \mathrm{pF}$

\section{MANUFACTURING YIELD}

The yield of this chip during development was calculated by FASTRACK using the previously mentioned Monte Carlo techniques. Because Harris was asked to perform only DC tests on the wafer probe, the yield was based on DC parameters including power supply currents and offset voltages. The parametric yield, assuming a single circuit per chip, was $78 \%$. The wafer run on which this circuit was included consisted of 10 wafers with 23 of the RHIC die per wafer (a single wafer consisted of $\sim 800$ die total of all the projects). The actual yield for this die was $61 \%$ given that two of the ten wafers were rejected. If these two wafers are not included, the RHIC die yield for the remaining eight wafers was $77 \%$.

\section{NOISE PERFORMANCE}

The noise analysis of the traditional grounded-emitter topology has been well documented previously ${ }^{6}$ and will not be repeated here because many noise sources are common to both topologies. Of interest, however, are the contributions of the additional noise sources unique to this topology. Figure 6 is a simulation plot of preamplifier output spot noise versus frequency for the dominant noise generators. The obvious contributors to preamplifier-generated parallel noise are normally the feedback resistor and the base (or gate) current generated by the input transistor. At low trequencies, the feedback resistor RF and the input base current of QIN1 are dominant sources predicted in the classical cascode analysis. In addition, this topology add $s$ two other sources, the base currents of Q9 and Q10. These sources appear predictably as part of the low-frequency parallel noise. At frequencies above $4 \mathrm{MHz}$, the series noise sources of QIN1 (collector shot noise and base spreading resistance) dominate as expected. The HSPICE overall predicted noise agrees very well with the measured noise, as shown in Table I.

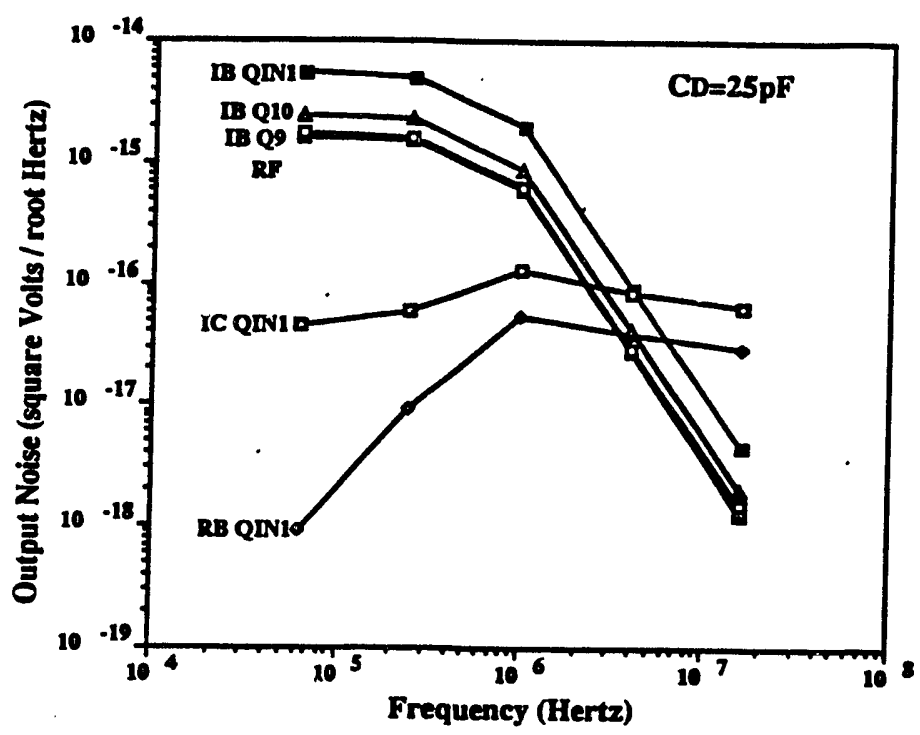

Fig. 6 Plot of simulation of output noise vs. frequency for dominant noise generators

Table I

Simulated vs. Measured Noise

\begin{tabular}{|c|c|c|}
\hline$C D$ & Simulated & Measured \\
\hline $10 \mathrm{pF}$ & $1700 \mathrm{e}^{-}$ & $1500 \mathrm{e}^{-}$ \\
\hline $25 \mathrm{pF}$ & - & $2200 \mathrm{e}^{-}$ \\
\hline $50 \mathrm{pF}$ & $3100 \mathrm{e}^{-}$ & $3500 \mathrm{e}^{-}$ \\
\hline
\end{tabular}

\section{POWER SUPPLY REJECTION}

In a large detector system, an almost certainty is that noise and voltage fluctuations will occur on the power lines going to electronics. Truly differential, high-gain amplifiers can typically be made to exhibit greater than $50-60 \mathrm{~dB}$ of power supply rejection at moderate frequencies. The fast, low DC gain (typically 2000 to 5000 ) amplifiers typically used for charge-sensitive preamplifiers at shaping time $<100 \mathrm{~ns}$ are more difficult to make with low power supply sensitivity. Part of the problem occurs because the input is a single-ended device and there is, therefore, little, if any, of the commonmode cancellation possible with a differential pair. Also, the input collector biasing was done using a resistor for purposes of low noise instead of using a current source which would improve the rejection somewhat. This preamplifier has a measured voltage gain from the power supply rails to the output of less than $-17 \mathrm{~dB}$ at frequencies $<100 \mathrm{KHz}$ for the 
positive supply and $-24 \mathrm{~dB}$ at frequencies $<100 \mathrm{KHz}$ for the negative supply. This result compares favorably with the simulated values of $-14 \mathrm{~dB}$ and $-21 \mathrm{~dB}$ for positive and negative respectively. The preamplifier tests (other than power supply rejection) were performed with $29 \Omega$ resistor in series and a $0.1 \mu \mathrm{F}$ capacitor in parallel with each supply pin. This combination gave filtering above approximately $50 \mathrm{KHz}$. Because the center frequency of a $\mathbf{5 0}$ ns peaking filter lies near $3 \mathrm{MHz}$, this filtering was found to be quite adequate.

\section{CHANNEL-TO-CHANNEL COUPLING}

The measured channel-channel coupling was approximately $-30 \mathrm{~dB}$. The reason for this value is that in the ceramic dip package version of this chip, the substrate was not tied to any reference and was left floating. In the final packaging, the substrate would be tied to ground and we would expect to see much better isolation.

\section{SHORT-CIRCUIT PROTECTION}

During assembly and testing, one problem that can occur is shorts on printed circuit boards due to solder splashes, failed components, etc. One would desire that the integrated circuits be protected and not self-destruct under fault conditions. Short circuit output protection occurs in this preamplifier because the output devices were sized such that the desired current would be supplied to the subsequent shaping amplifier, but the current gain hFE would be drastically reduced for a short to ground or to a power supply, thus effectively tying the output to the fault through a silicon resistor. Upon removal of the fault, the preamplifier will return quickly to normal operation. The hFE vs. $I_{C}$ curve of a typical LN3 device (1 emitter stripe, 2 base stripes, ring collector) is shown in Fig. 7. IKF, the current marking the onset of high-level injection,is typically 10-20 mA. The associated PNP device has a similar IKF.

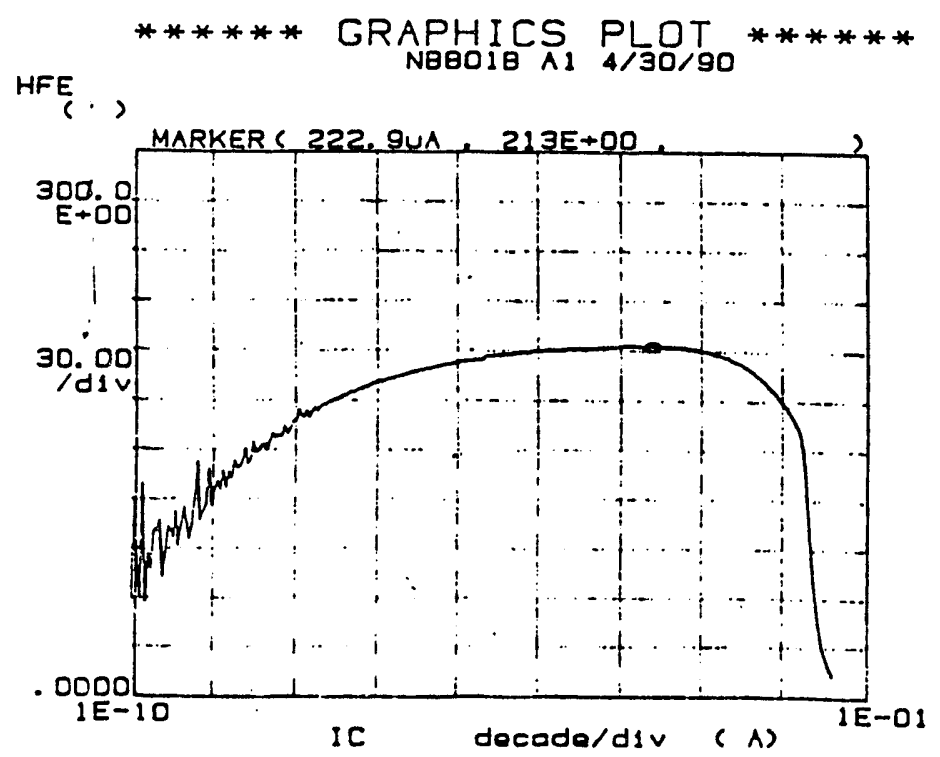

Fig. 7 hFE vs. $I_{C}$ for LN3 device
Another factor that contributes significantly to short circuit protection is the relatively large collector ohmic resistance for each transistor. For the LN3-size device, the collector ohmic resistance is typically $600 \Omega$. It is thus impossible to obtain very large output currents because of this series-limiting resistance.

\section{RADIATION EFFECTS}

A summary of the Harris device measurements both before and after gamma radiation has been published ${ }^{1}$. The quad preamplifier was irradiated with ${ }^{60} \mathrm{Co}$ to $1.25 \mathrm{MRad}$ with a dose rate of $33 \mathrm{KRad} / \mathrm{hr}$ and then tested. Pre- and postradiation performance is summarized in Table II. As can be seen, no change occurred in risetime or slew-rate, and only a small change occurred in the noise and power dissipation. Heavy ion and neutron irradiations were not performed because of the lack of a suitable source at the time of testing.

Table II

Radiation Performance Summary

\begin{tabular}{|c|c|c|c|c|}
\hline $\begin{array}{l}\text { Dose } \\
\text { (MRad) }\end{array}$ & $\frac{\text { Power }}{\mathrm{mW} / \mathrm{ch}}$ & $\frac{\text { Detector }}{\text { Cap (pF) }}$ & $\begin{array}{c}\text { Risetime (ns) } \\
\left.\text { / Noise (e } e^{-}\right)\end{array}$ & $\frac{\text { Slew Rate }}{(V / \mu s)}$ \\
\hline$\overline{0}$ & 10 & 9.7 & 11497 & 150 \\
\hline & & 25.7 & $5.8 / 2212$ & \\
\hline & & 52.7 & $9 / 3485$ & \\
\hline 125 & 0 & 07 & 1574 & 150 \\
\hline & & 25.7 & $5.8 / \ldots$ & \\
\hline & & 52.7 & $9 \quad / 3539$ & \\
\hline
\end{tabular}

\section{DISCUSSION}

The decision to pursue the consolidated readout approach ended our development of the bipolar version of this preamplifier. An all-CMOS integrated circuit designed at ORNL that includes preamplifiers, correlated samplers, analog memory pipelines, and ADC has been fabricated and is awaiting tests. If the CMOS front-end becomes unsuitable as development progresses, the bipolar approach will be resumed. The bipolar preamplifier will be used for some planned bench tests of the streamer tube-pad detector.

\section{CONCLUSIONS}

A full custom bipolar preamplifier fabricated in Harris Semiconductor VHF Process was described. Data for gamma pre- and post-irradiation to $1.25 \mathrm{MRad}$ indicated that the dynamic characteristics of the circuit were unchanged and that the biasing and noise showed only a few percent change after exposure to radiation.

\section{ACKNOWLEDGEMENTS}

We would like to thank Harris Semiconductor for the opportunity to be involved with the beta test of FASTRACK 
and the help they extended during the test. We would also like to thank Norma Hensley for her seemingly infinite patience during the preparation of this paper.

\section{REFERENCES}

1. E. J. Kennedy et al., Radiation Effects On JFETS, MOSFETS, and Bipolar Transistors, As Related to SSC Circuit Design, Nucl. Inst. Meth. A307 (1991) 452-457.

2. C. L. Britton, Jr., et. al., Bipolar Monolithic Preamplifiers for SSC Silicon Calorimetry, Proc. Symp. On Detector Research and Development for the Superconducting Super Collider, Oct. 1990, pp. 523-525.

3. R. Albrecht, et. al., Self-Quenching Streamer-Tube Detectors In the WA80 Experiment, Nucl. Inst. Meth. A276 (1989) 131139.

4. A. Abidi, On the Operation of Cascode Gain Stages, IEEE Jour. Solid State Ckts., Vol. 23, No.6, Dec. 1988, pp. 14341437.

5. W. Sansen and Z. Y. Chang, Feedforward Techniques for HighFrequency CMOS Amplifiers, IEEE Jour. Solid State Ckts., Vol. 25, No.6, Dec. 1990, pp. 1590-1595.

6. Veljko Radeka, Low-Noise Techniques In Detectors, Ann. Rev. Nucl. Part. Sci. 1988. 38: 217-277. 


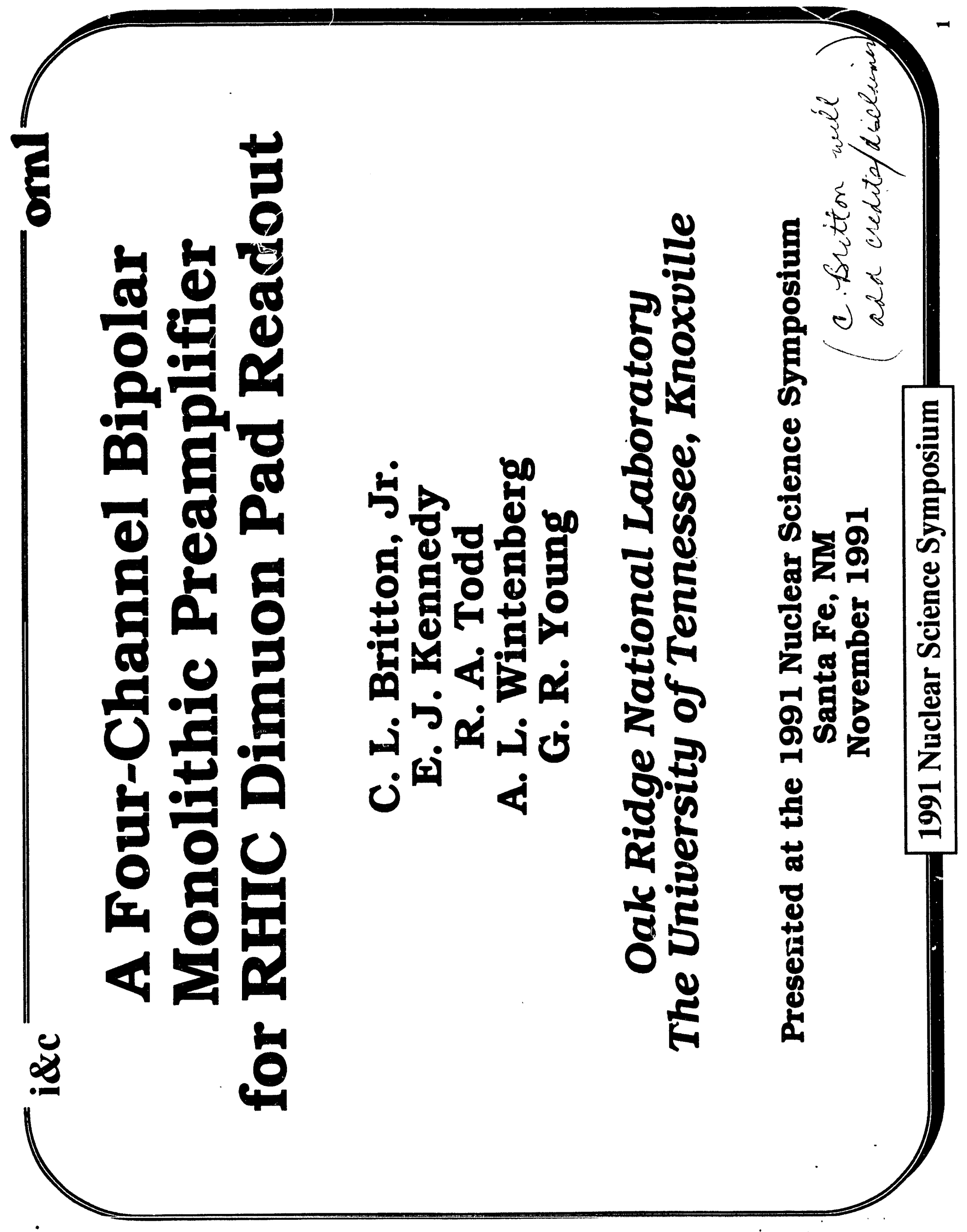




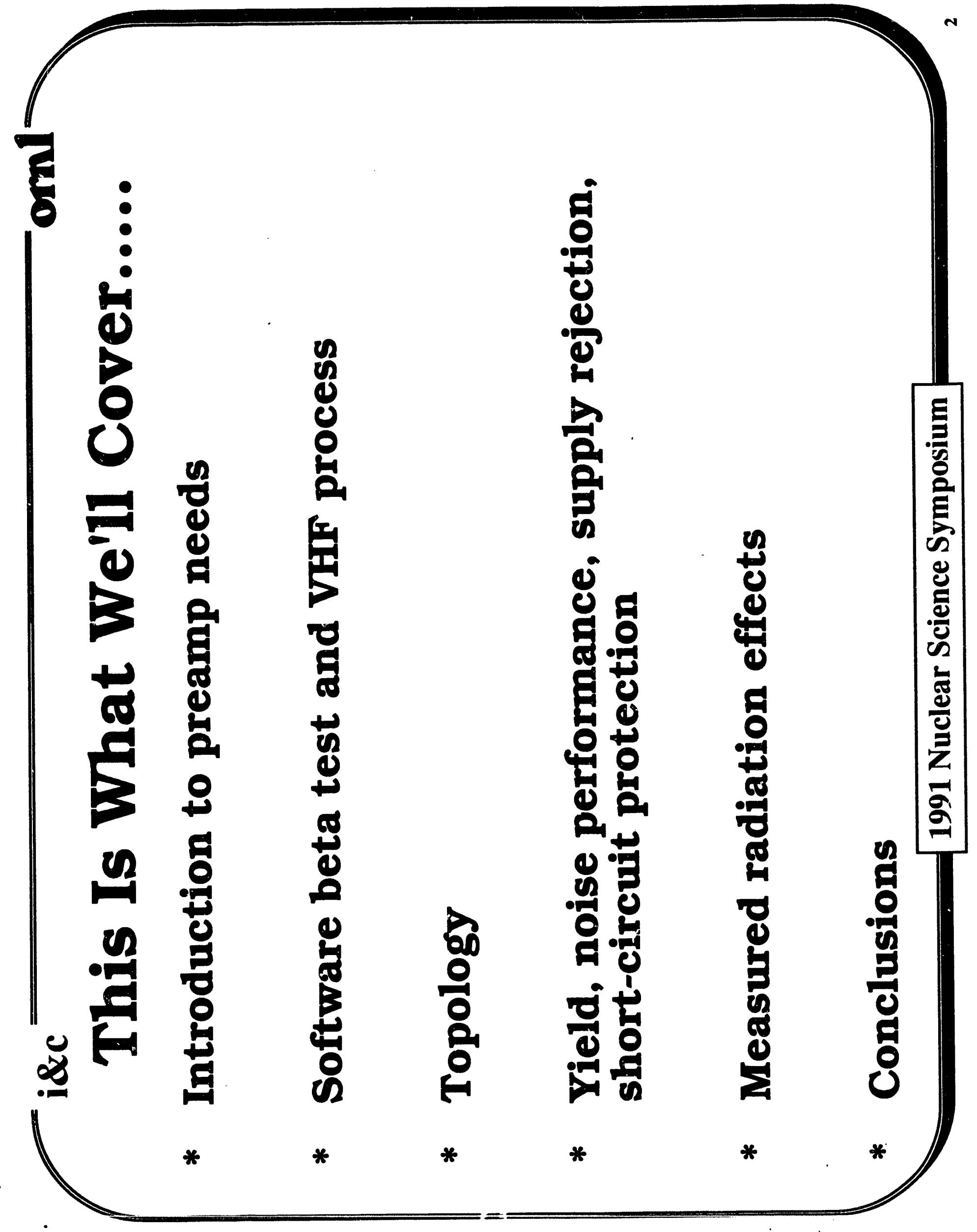




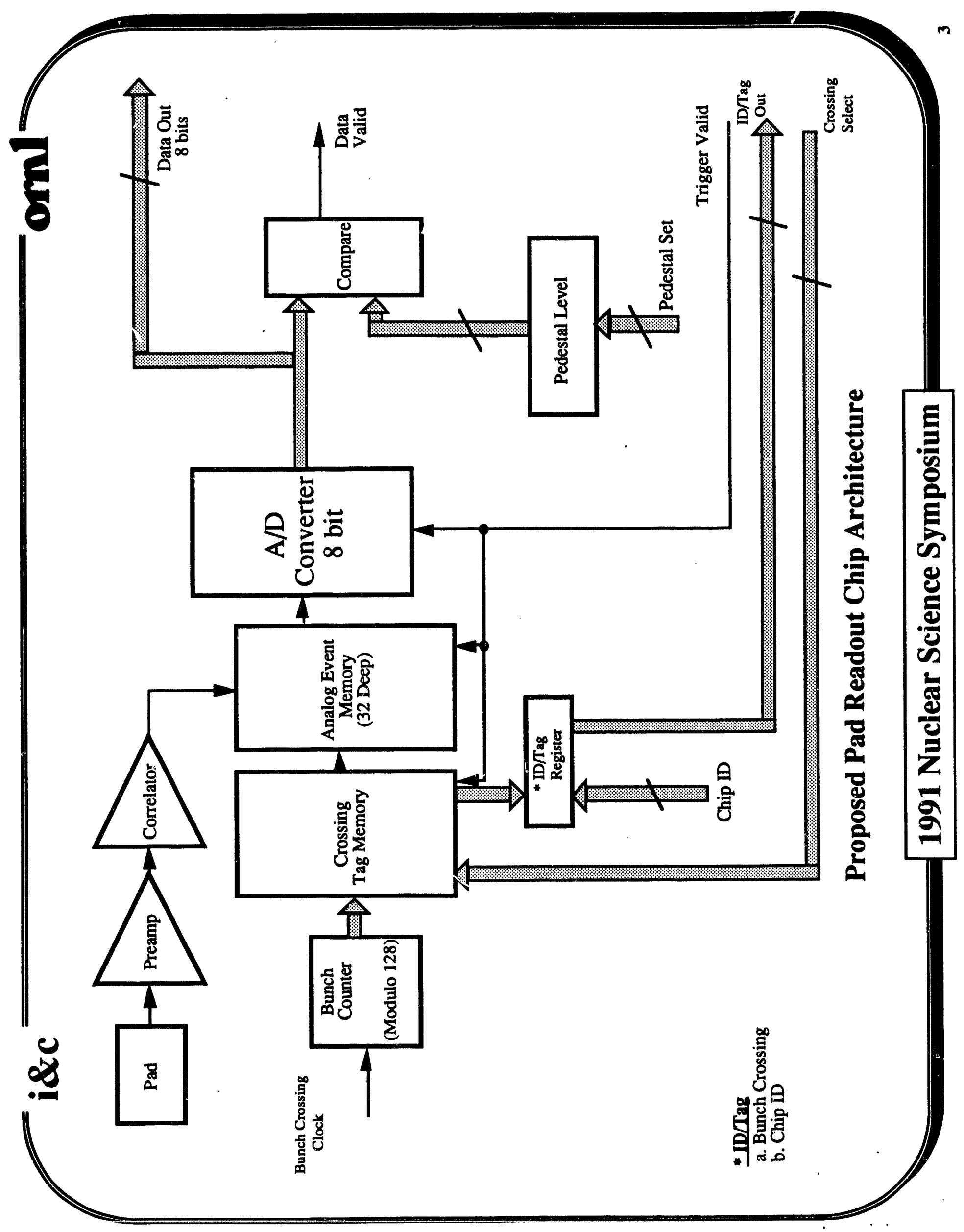




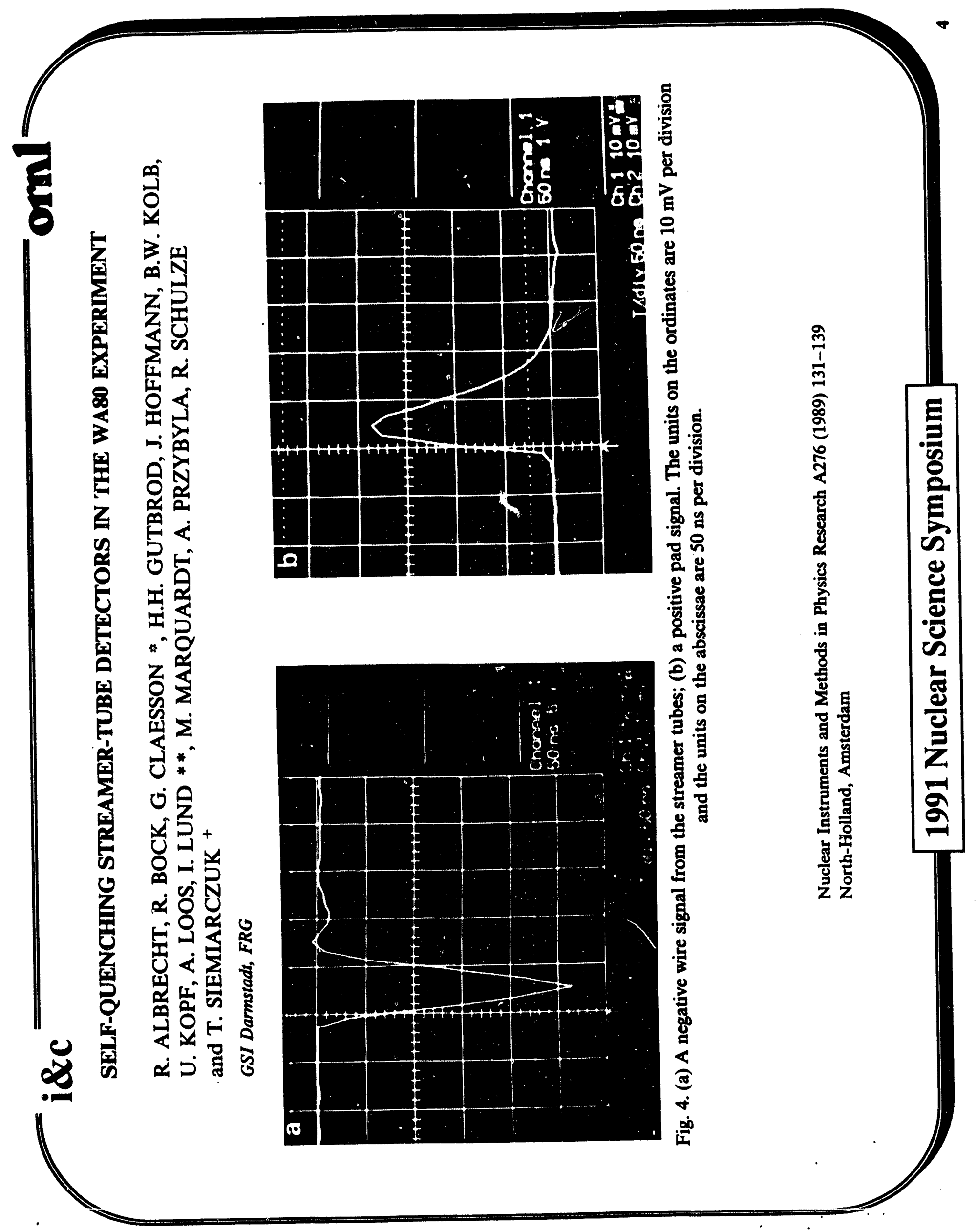




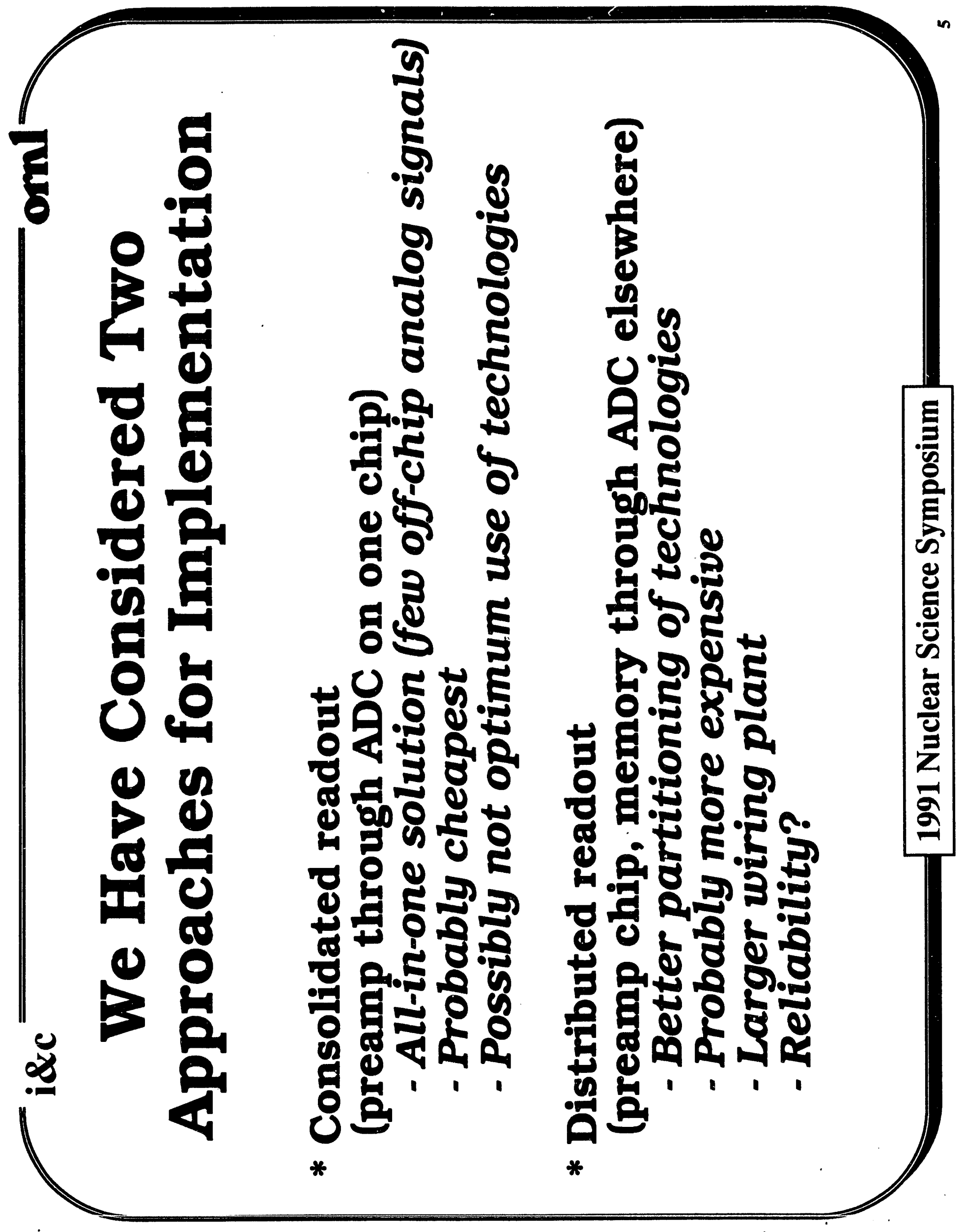




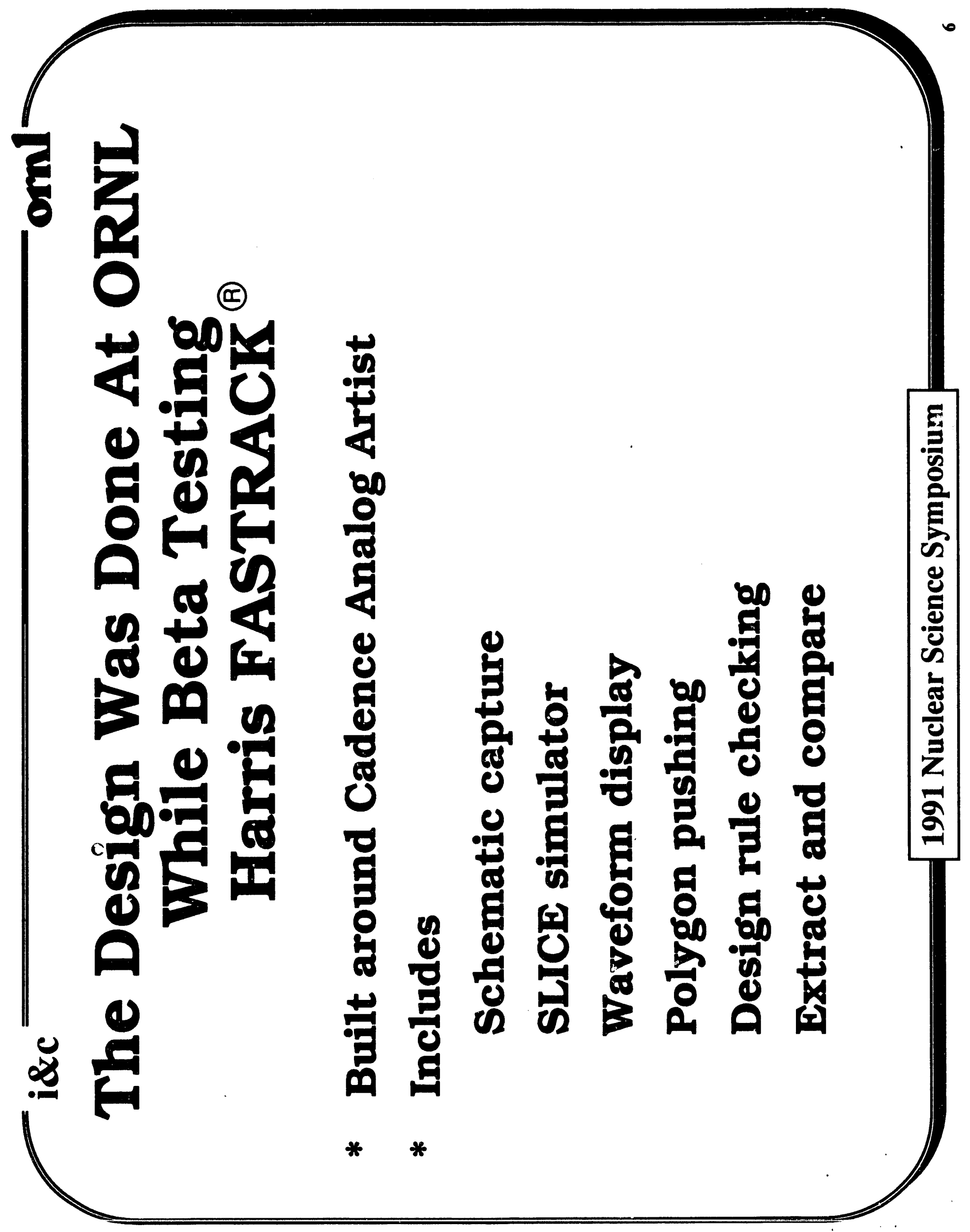




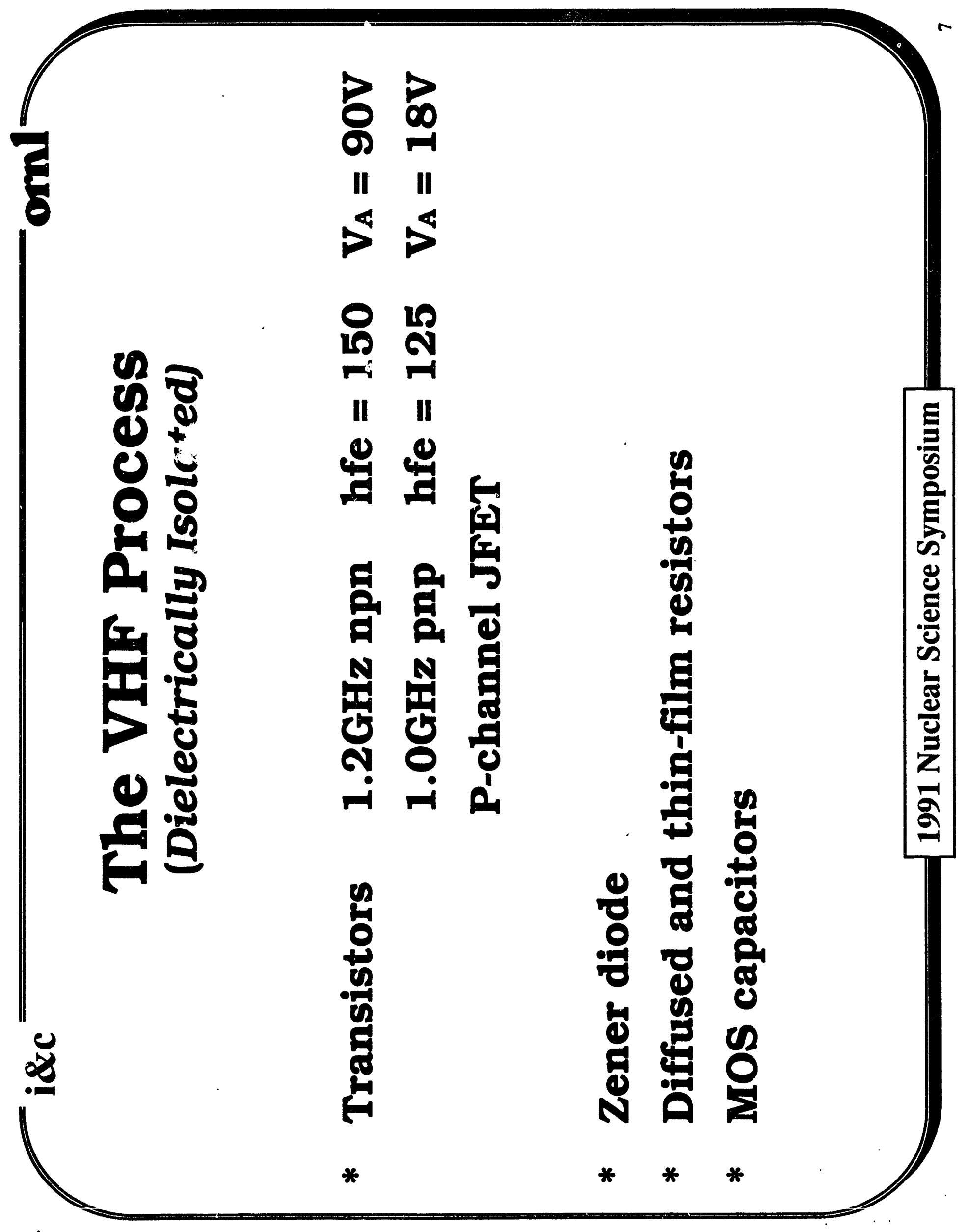




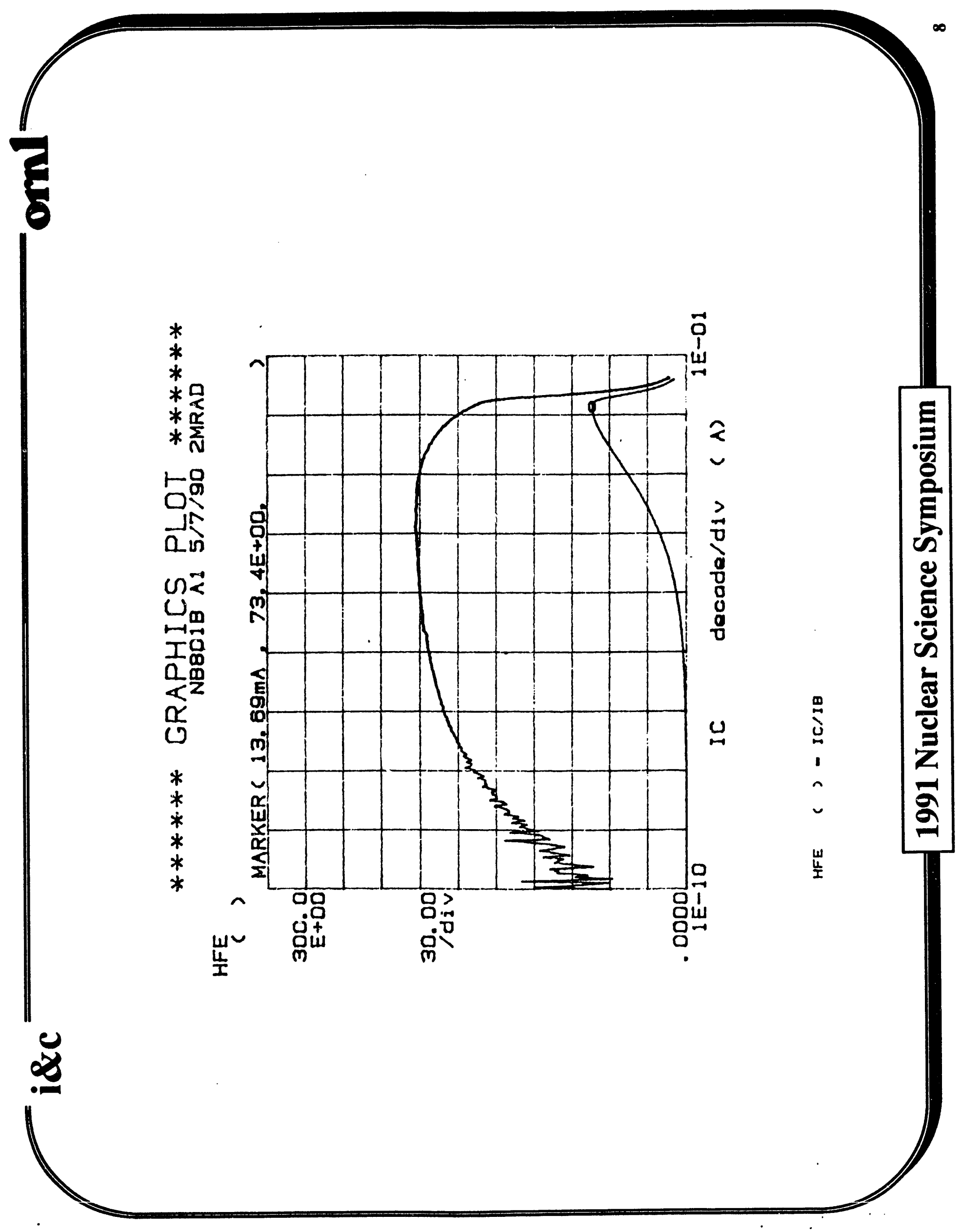




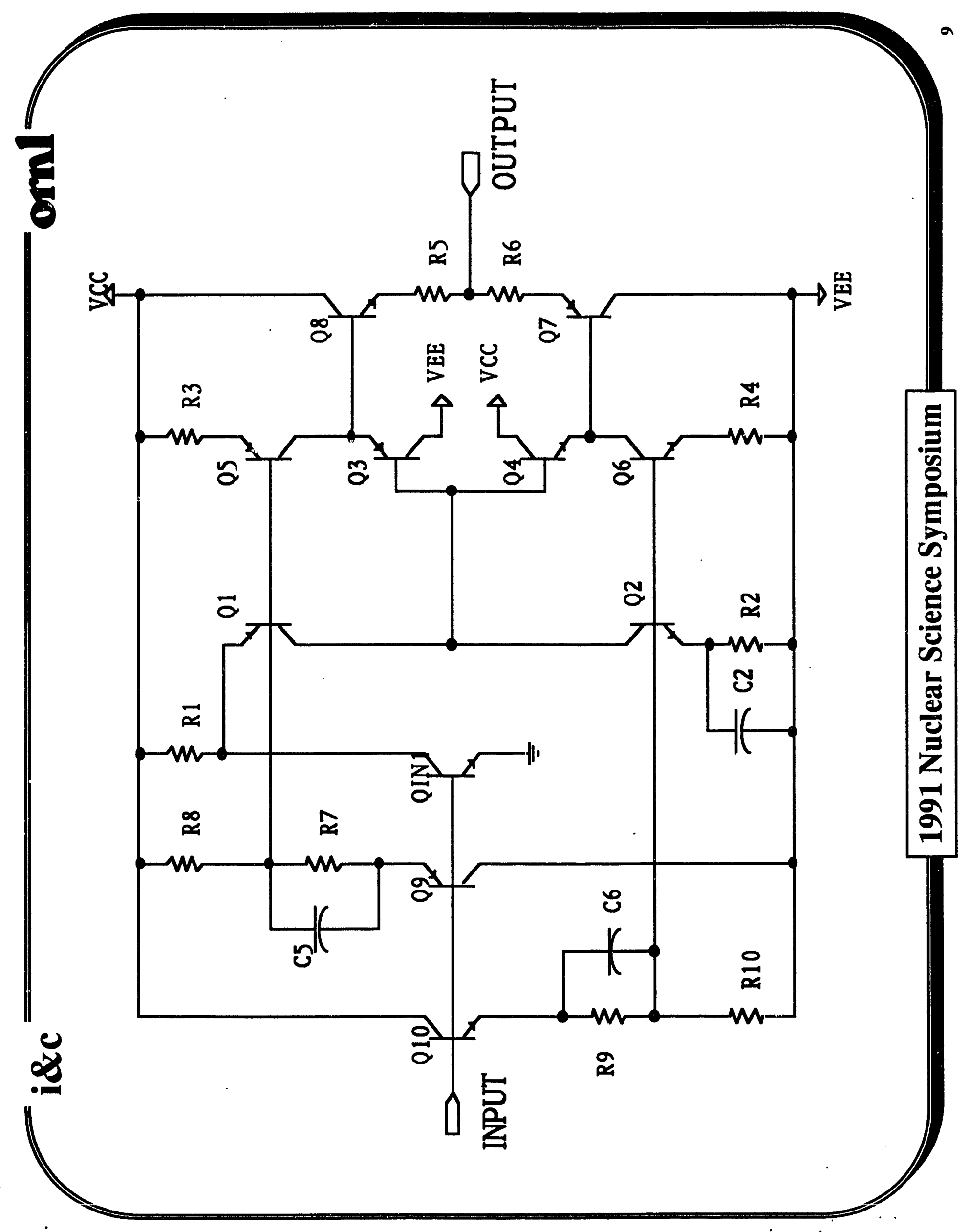




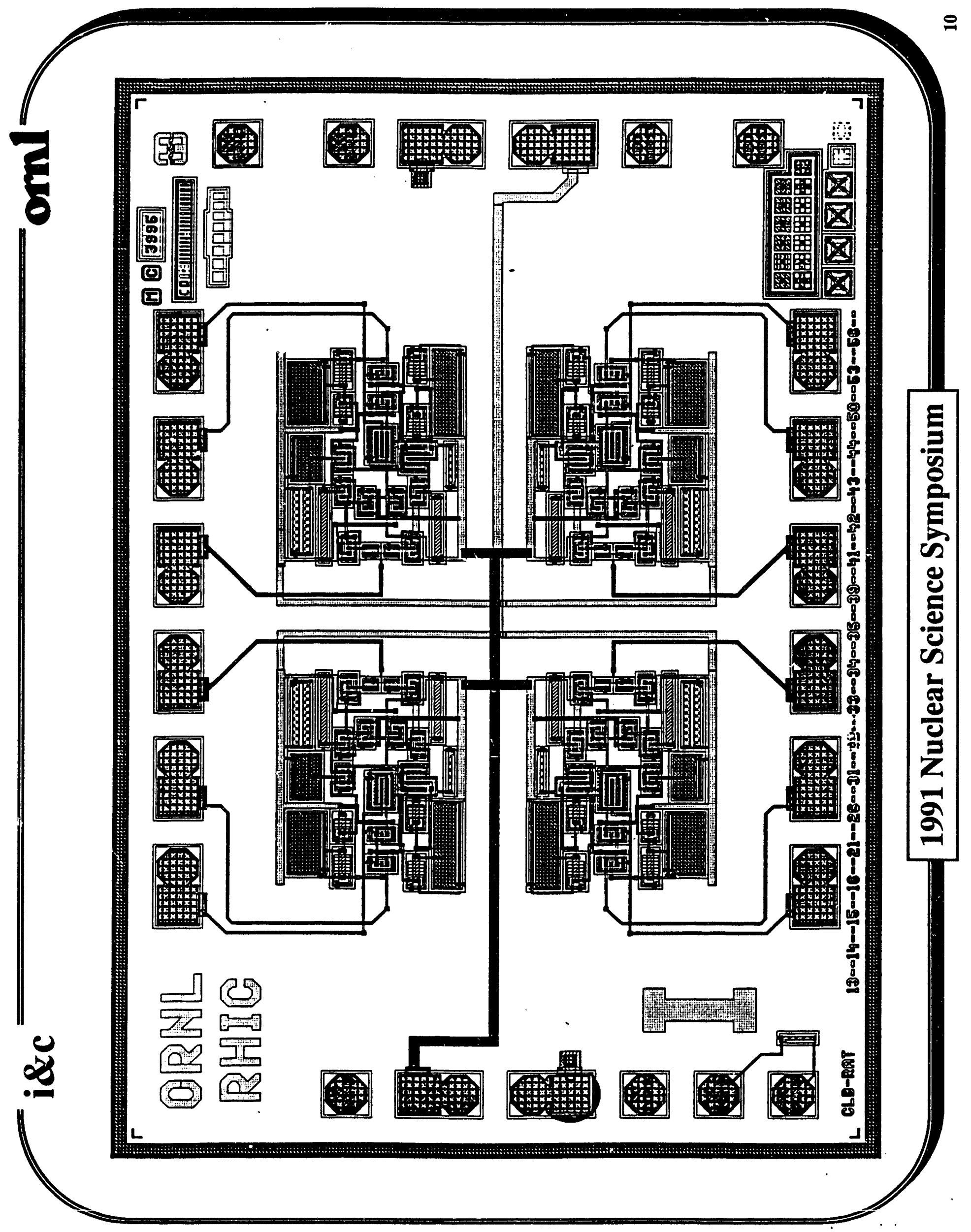




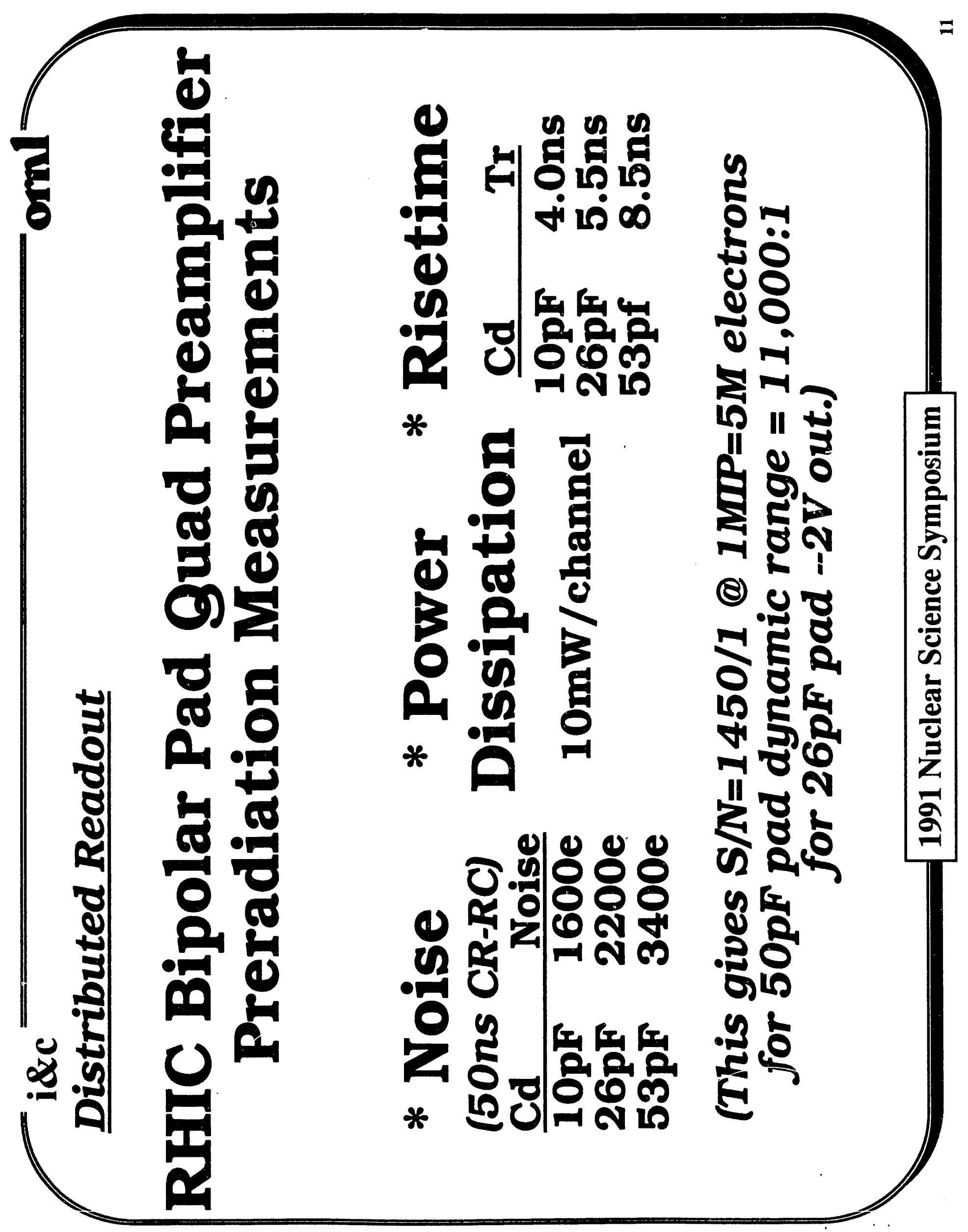




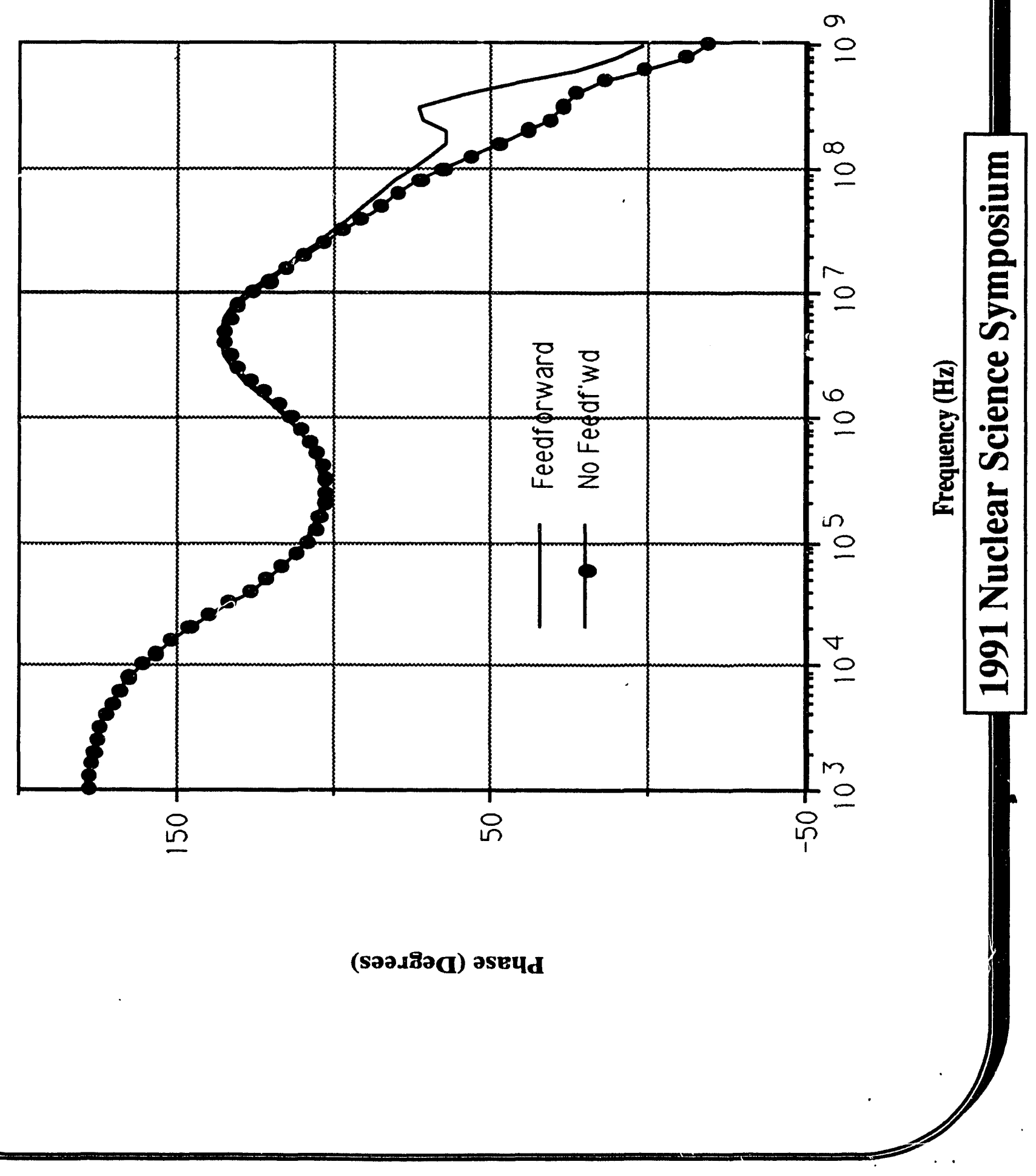




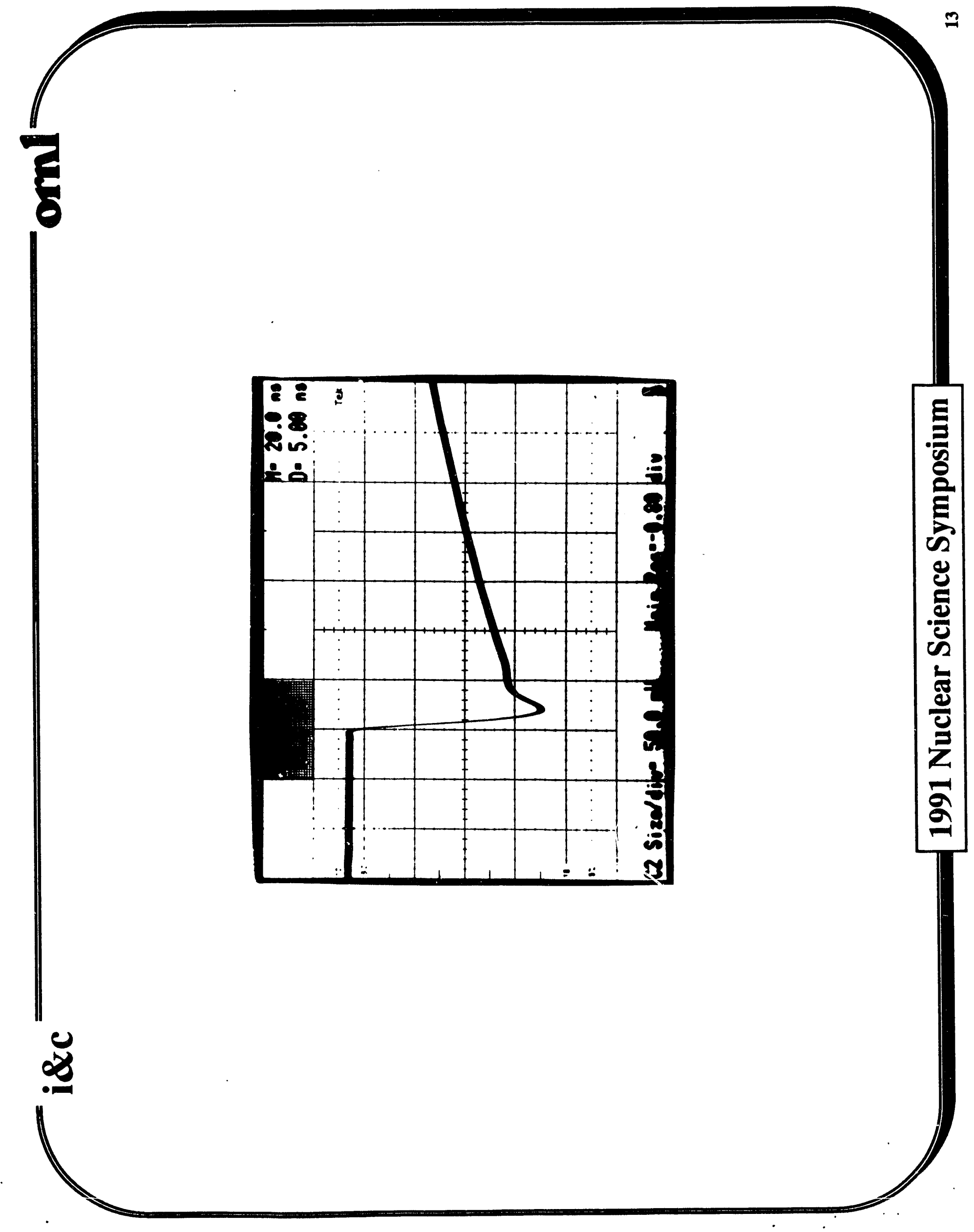




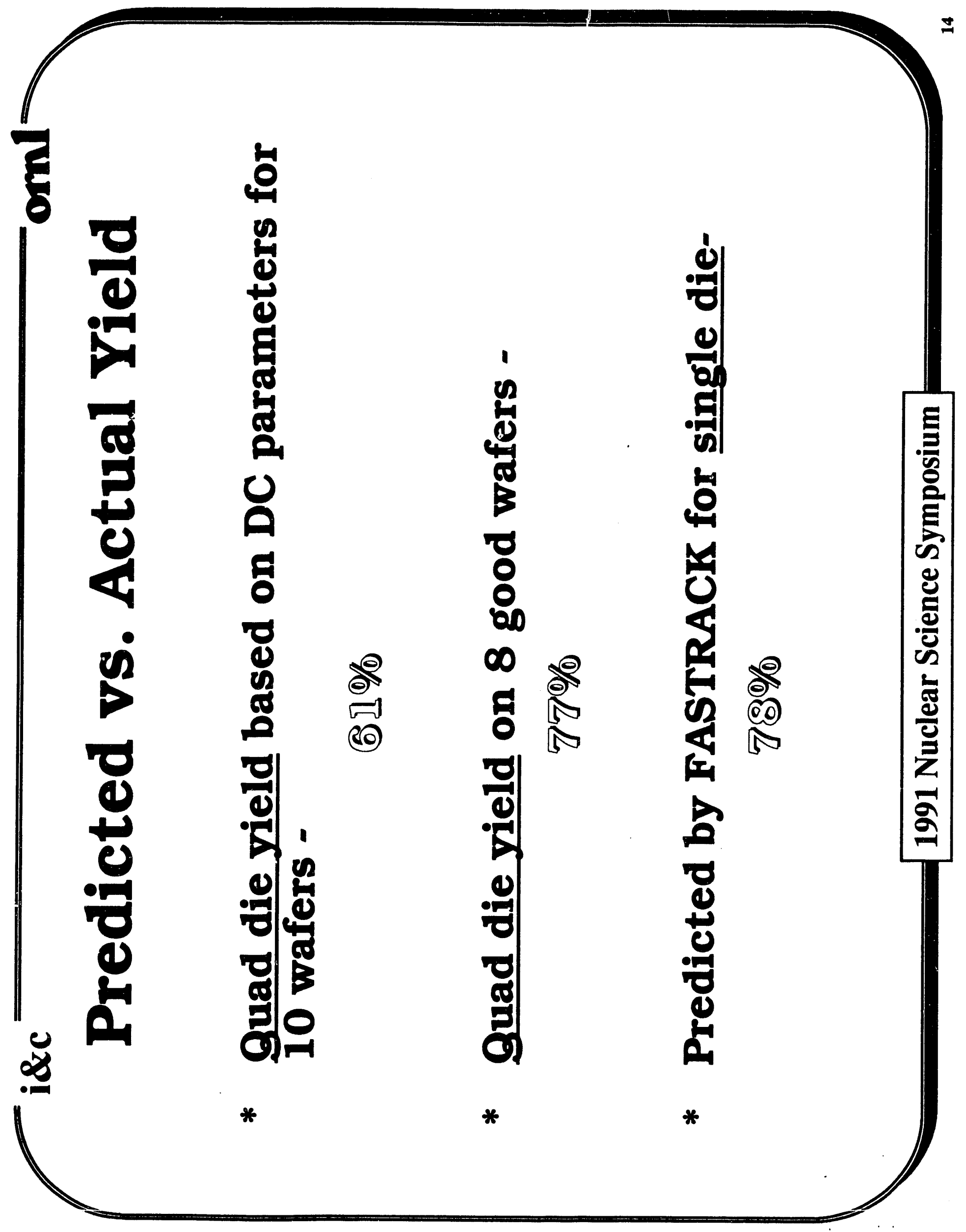




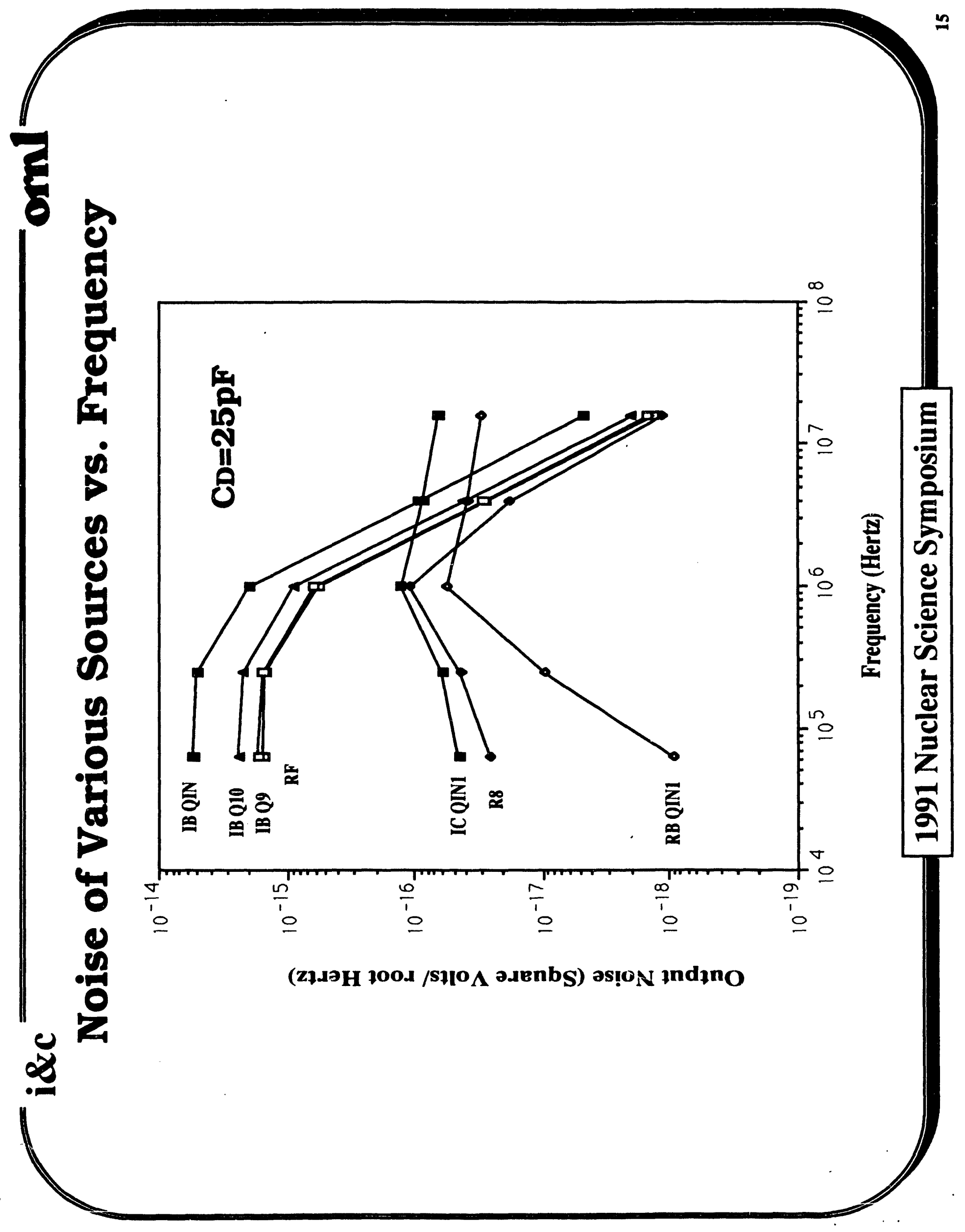




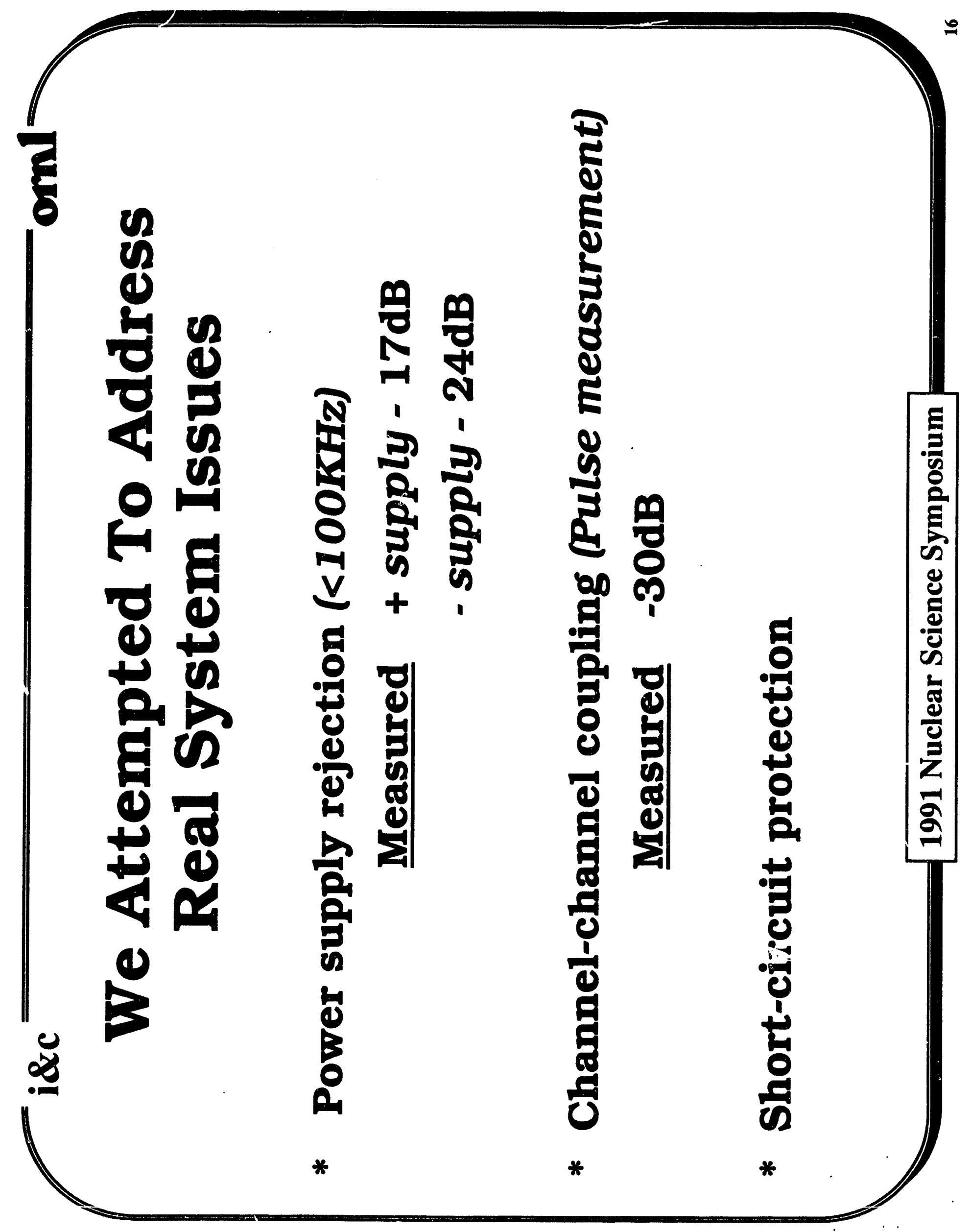




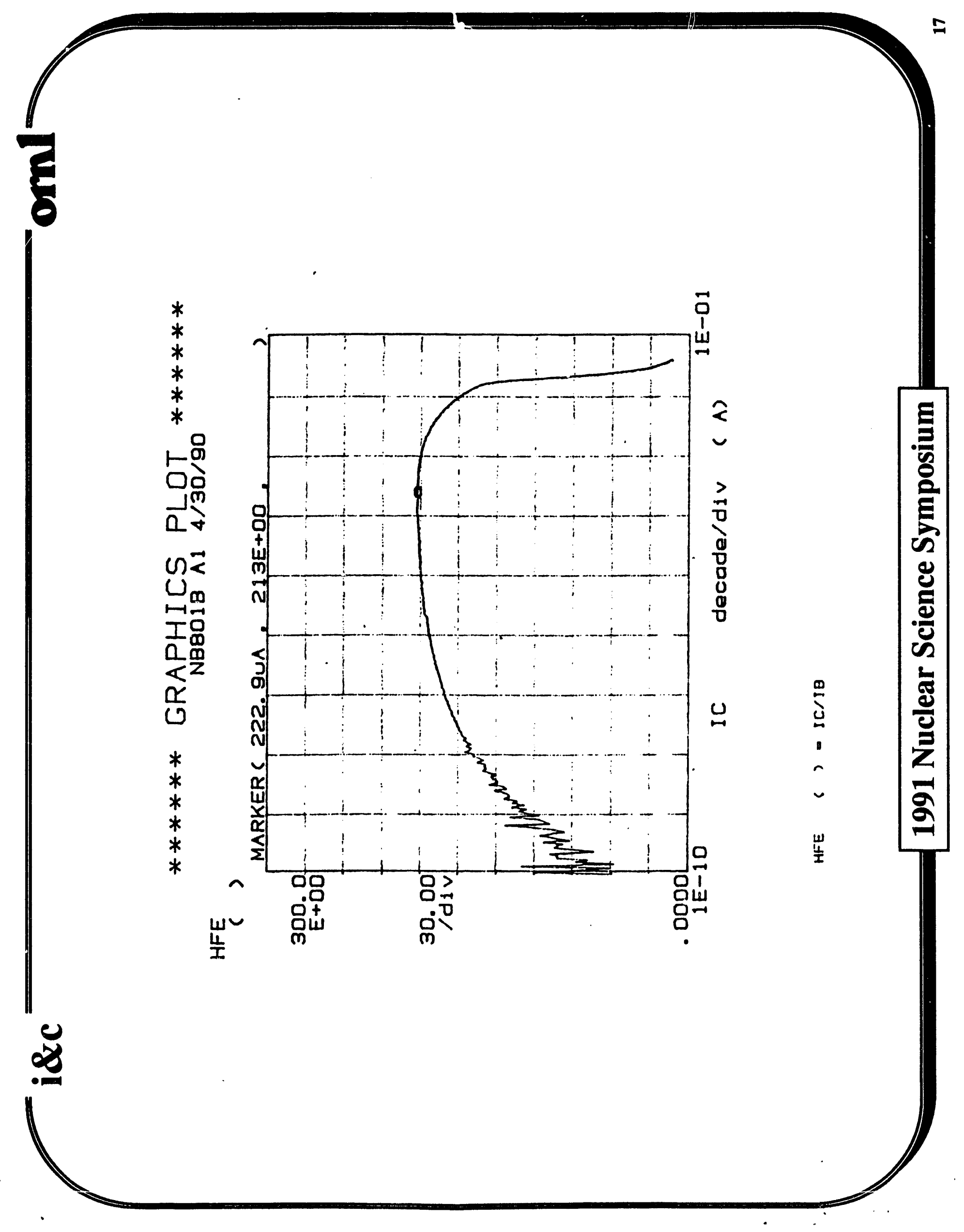




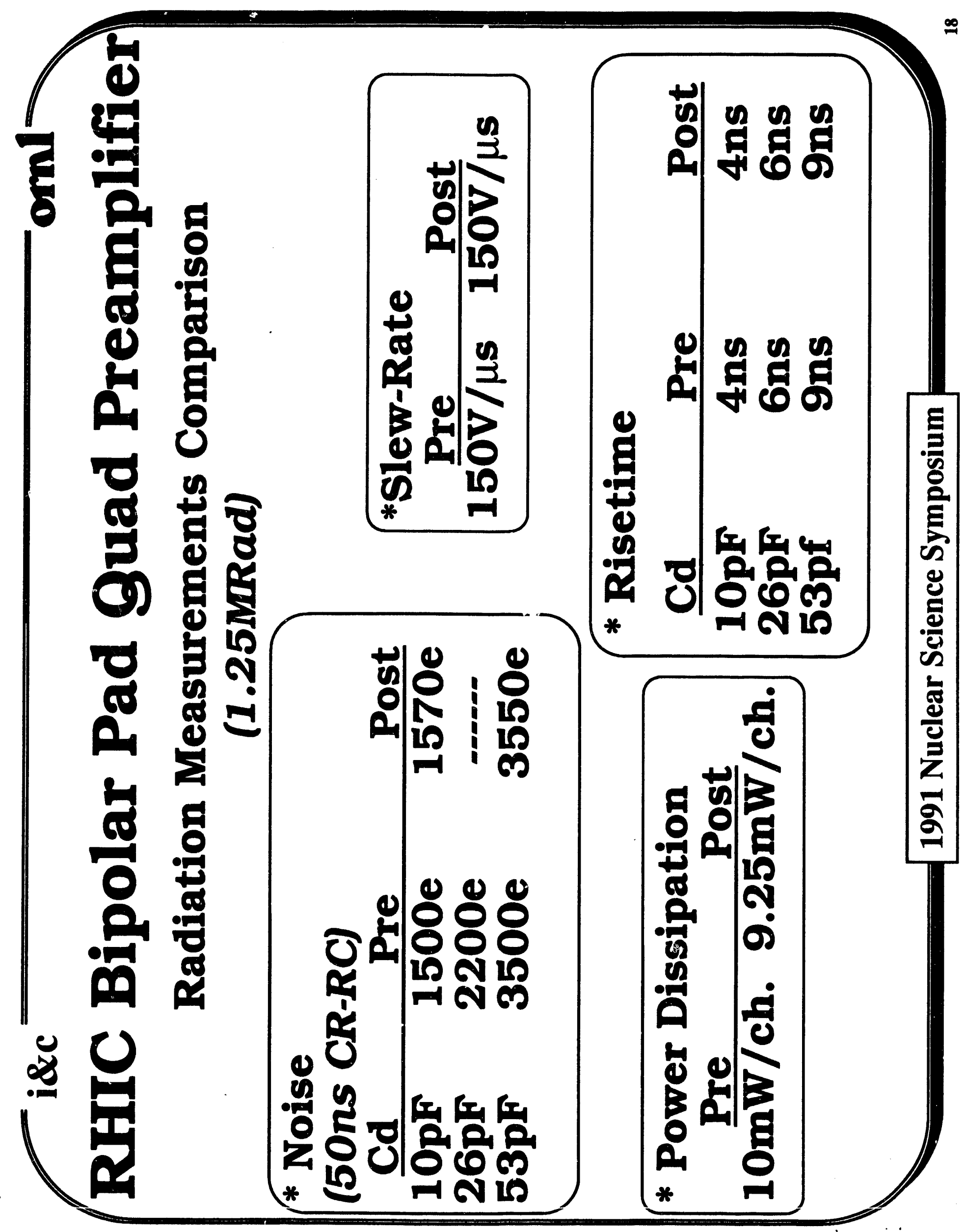




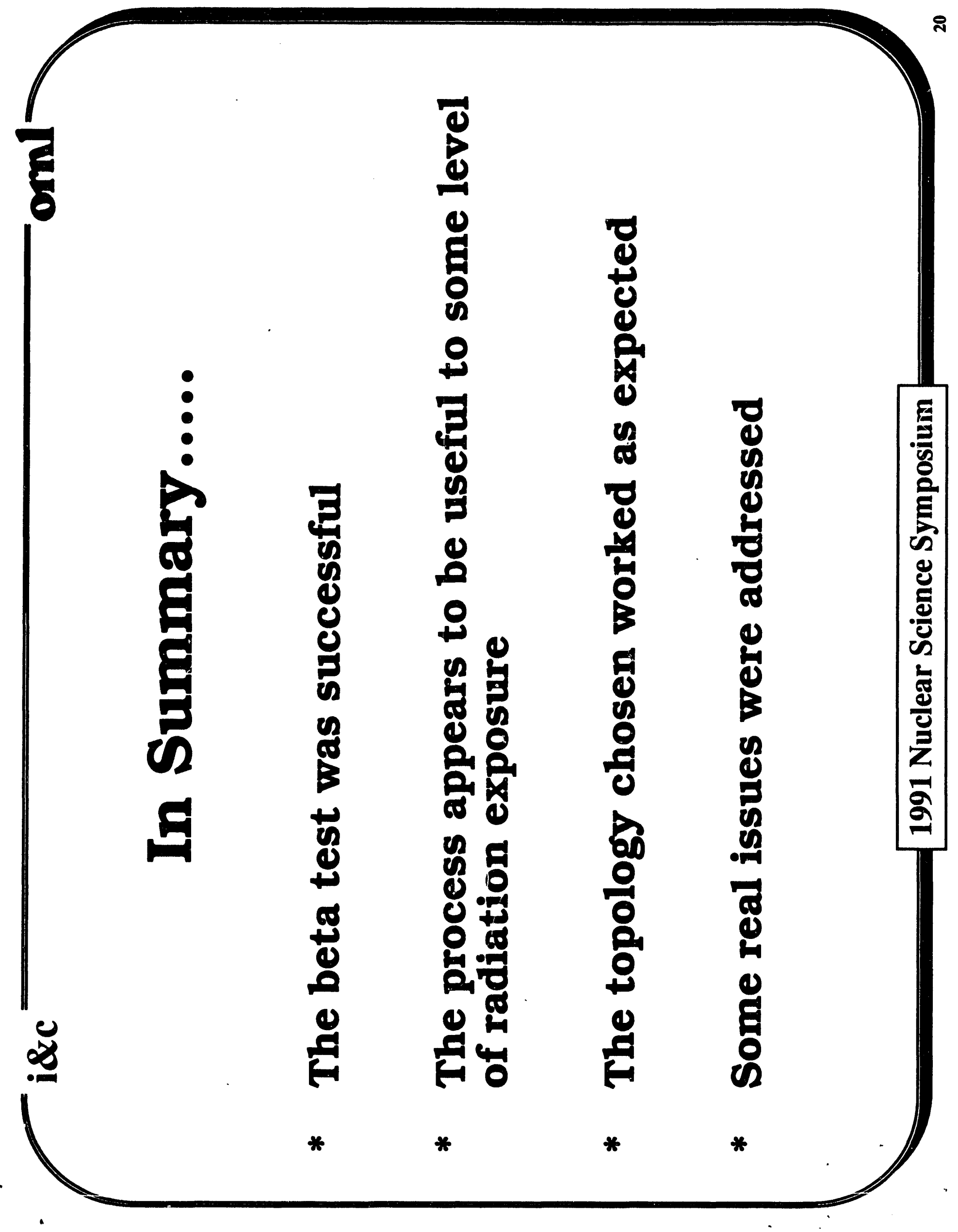



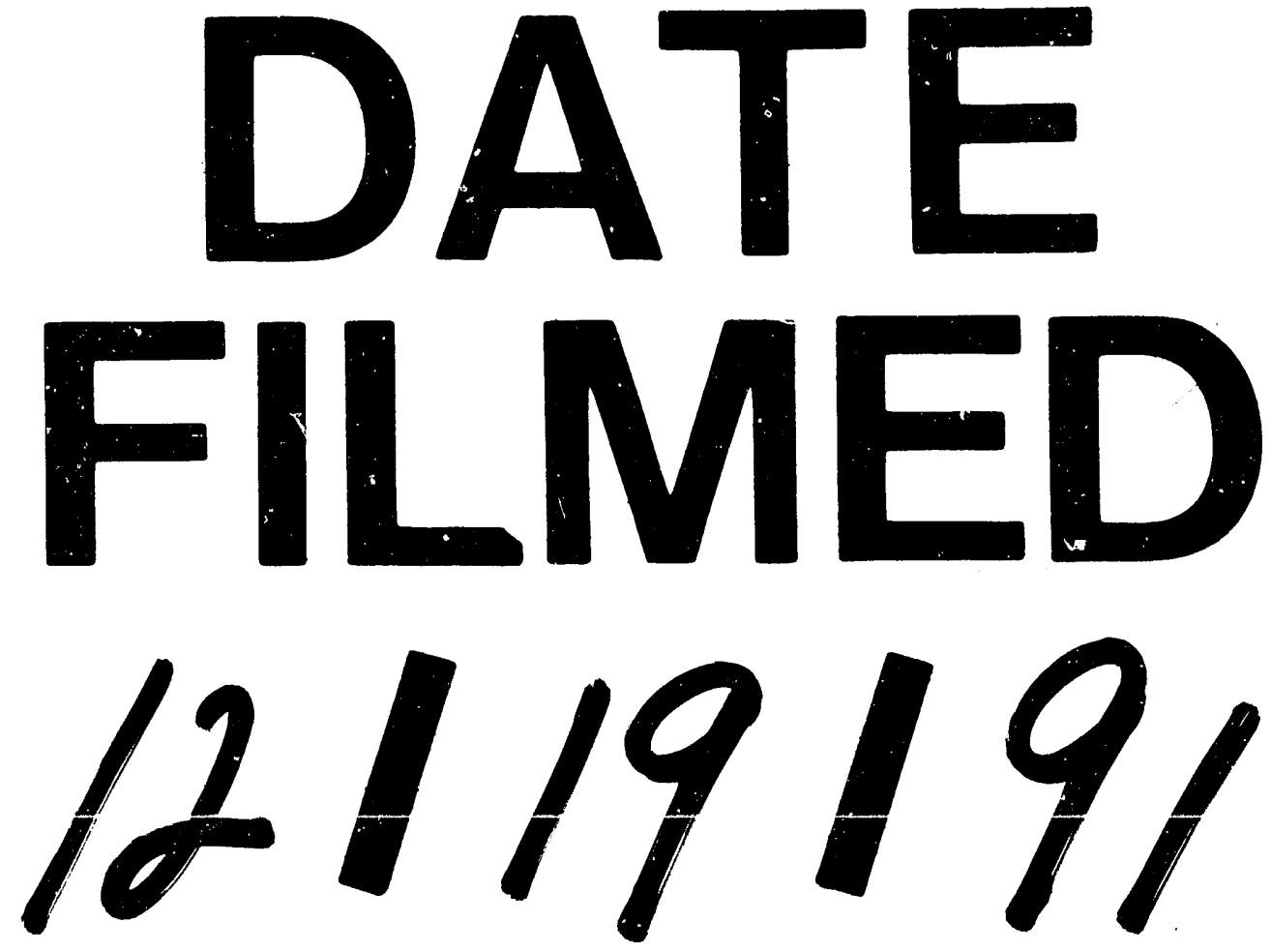

T) 
